\title{
Sensor Based Fault Detection System for Efficient and Effective Street Lighting
}

\author{
${ }^{1}$ Srija Reddy Kamidi, ${ }^{2}$ Bhanuprakash Vardhaman, ${ }^{3}$ Priyanka Belide, ${ }^{*}$ Ramsha Karampuri \\ ${ }^{1,2,3,4}$ Centre for Emerging Energy Technologies, S R Engineering College, Warangal, Telangana, India. \\ Email: ${ }^{1}$ srijareddy0810@gmail.com, ${ }^{2}$ vardhamanbhanu2601@gmail.com, ${ }^{3}$ priyabelide05@gmail.com, \\ ${ }^{4}$ ramsha.karampuri@gmail.com
}

Received: 06th October 2019, Accepted: 20th November 2019, Published: 31st December 2019

\begin{abstract}
The smart street lighting system is being introduced in the smart cities of India. Smart street lighting systems use various sensors. In this paper, three different sensors are proposed to be used in the smart street lighting systems which work in coordination with each other. The Light Dependent Resistor (LDR) sensor to differentiate the day and night time, InfraRed (IR) sensor to detect the movement of an object and the photodiode to monitor the health of the Light Emitting Diode (LED) lights. The proposed system is costeffective and results in improving the overall efficiency.
\end{abstract}

Keywords

Controller, Light Emitting Diode, Sensors, Smart City, Street Light.

\section{Introduction}

Increase in the population is leading to the vast spread of major cities in India. Expansion of the city geography is resulting in the increased power consumption [1-3]. One of the major loads of power consumption in the city is by the street lights. In the olden days, the street lights were turned ON or OFF by the personnel, which involves high risk of human error. Later, timer based control of street lights has been introduced, where the street light gets turned ON or OFF based on the time setting. This does not involve the climatic changes or seasonal changes, which leads to the excess power loss.

Recently, many researchers have published papers on the usage of LEDs for street lights and their control in a conventional way and the smart way [4-15]. However, all the papers cited in this paper do not discuss about the fault detection of the LED lights, which is a major problem facing by many street walkers. The faulty street lights generally used to take longer time to replace. This paper proposes a solution for the smart street lighting system using three different sensors working in the coordination and the Internet of Things (IoT) platform.

The features of the proposed solution are: it is highly reliable system, most economical, user friendly, easy to maintain, most importantly fault detection made easy. In addition, the major benefits by adopting this system are: power saving about $40 \%$, economy saving in the form of electricity bill is about $40 \%$, increased life span of LEDs and the payback period is only about one year.

In the following sections, a brief explanation of the proposed system is presented. Also, the working of the proposed system is explained in the third section. Fourth section gives the cost analysis and the last section concludes the work.

\section{System Description:}

The proposed system shown in Fig. 1 mainly consists of sensors like InfraRed (IR) sensor, Photodiode sensor, Light Dependent Resistor (LDR) sensor, Light Emitting Diodes (LED) as load, Controller ESP-32. The each part of system is explained in detailed in the following subsections.

\section{IR Sensor:}

In the proposed system, IR sensor is used to detect the moment of any object either it is human or any other metal. By the basic principle of IR sensor, it detects motion and sends the signal to the LED (physical to electrical) via controller then the led glows. The working range of IR sensor can be adjusted using the preset inbuilt on the resistor or by selecting appropriate model of IR.

\section{Light Dependent Resistor (LDR):}

LDR is used in the proposed system to sense the light intensity of the surroundings. When the light intensity is high the LED is turned OFF and when the light intensity is less the LED is turned ON. By this we can ON LED at low intensity of light. This is also done through the controller. 


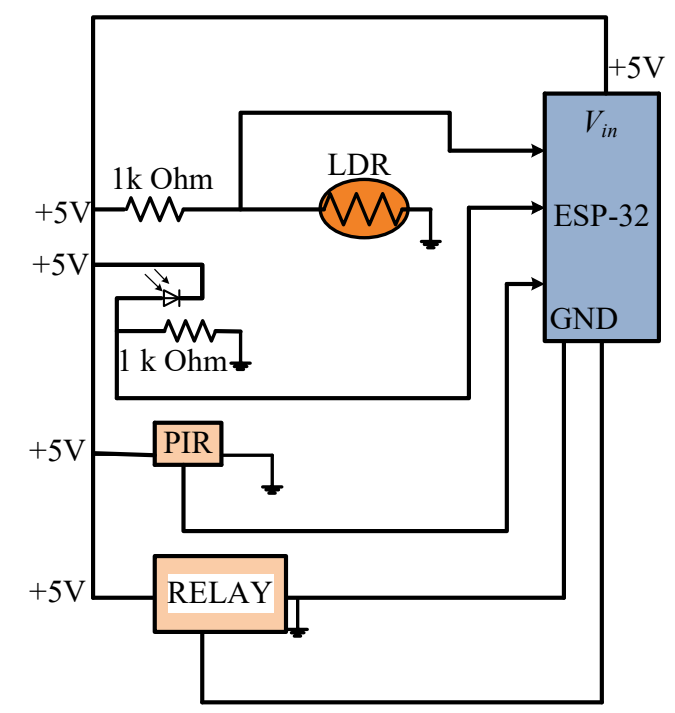

Photodiode:

Fig 1: Functional Diagram of the Proposed Sensor based Street Lighting System.

It this system, the photodiode is used to know whether the LED light is in good condition or not; simply it helps in fault detection of LED light which is the major issue facing in these days. When the photodiode is placed in the vicinity of LED the light falls on the diode and it conducts. Otherwise, the photodiode do not conduct and in standstill mode. This photodiode is connected to the controller which senses the value 0 or 1 based on the conducting status of the diode. This information is uploaded to the cloud through the Internet of Things (IoT) platform. This helps in easy and in-time maintenance of the LED street lights.

\section{Controller ESP-32:}

The main purpose of using ESP32 is - it consists of Wi-Fi modules which can be accessed vary easily and quickly. It can also be used in the central operating system. It is a type of controller with n-number of inputs consisting n-number of functions. We can use ESP32 to connect more LED connections for one controller.

Relay:

The relay is used to operate or turn ON and OFF the LED. The control signal from the controller ESP32 is given to the relay and the main power supply to the LED street light is connected through the relay.

\section{Working of the Proposed System:}

The whole system works under the basic principles of all the sensors used and all the sensors are placed in their respective positions. In the proposed system, there are three types of sensors used and their working is explained in below lines clearly. Working procedure can be explained in detail with block diagram as shown in Fig. 1.

Here for LDR sensor, when light rays falls on LDR (when exceeds the selected range only), the resistance value of LDR get increased, so that the current flow decreases. As LED is connected to LDR through relay, LED gets TURN OFF. Similarly, when LDR is in dark condition (below specified range) then the resistance gets reduced and current flow increases to its rated value, which will be detected by the controller. The controller turns ON the LED light through the relay.

Even under dark conditions i.e., night times, the power consumption of LED lights can be reduced by controlling them with respect to the movement of pedestrians and the vehicles. The working of IR sensor is to sense the motion of an object either pedestrian or a vehicle. When the IR sensor is used in its position and when it detects the metal or any other things while they are moving IR sensor passes information to the controller and then to the relay which turn ON the LED light. The LED light should turn ON when the vehicle or any pedestrian is at previous street light. The main objective is the LED must turn ON only under dark conditions and when the objective is detected by the IR sensor as shown in Table 1. It says that LDR resistance must decrease and IR must sense an object then LED get turn ON.

The other sensor used in the system is the photodiode. It is placed inside the LED streetlight. When LED is turn ON by satisfying the above condition, photodiode sends information to the controller which uploads the information to the cloud. By reading the information from cloud, one can understand the position of the LED and can estimate the life span of the LED.

Table 1 depicts all conditions as discussed above and are divided into four categories of operation as follows:

Case -1: Day time and no object detected hence LED should be in turned OFF state. Fault detection should not work because it is not a fault in this case.

Case-2: Day time and objects are detected; even then LED should not get turned ON. Also, fault detection should not work because it is not a fault. 
Case-3: Night time and no object is detected hence LED should be in turned OFF state. Fault detection should not work because it is not a fault in this case.

Case -4: Night time and object is detected hence LED should get turned ON. Now in this case if the LED did not get turned $\mathrm{ON}$, then it is treated as faulty condition, otherwise healthy operation.

From all the above cases, only case 4 is monitored and uploaded to the cloud, which helps in easy monitoring of the faulty LEDs and have timely replacement. The experimental prototype of the proposed system is developed in the laboratory and its photograph is presented in Fig. 2.

\begin{tabular}{|c|c|c|c|c|}
\hline Case & $\begin{array}{c}\text { LDR } \\
\text { Day }=0 \text {, } \\
\text { Night }=1\end{array}$ & $\begin{array}{c}\text { IR } \\
\text { No object }=0 \text {, } \\
\text { Object }=1\end{array}$ & $\begin{array}{c}\text { LED } \\
\text { OFF }= \\
0 \\
\mathrm{ON}=1\end{array}$ & $\begin{array}{c}\text { Fault } \\
\text { Detection } \\
\text { Faulty }=0 \\
\text { Healthy }= \\
1\end{array}$ \\
\hline 1 & 0 & 0 & 0 & $\mathrm{X}^{*}$ \\
\hline 2 & 0 & 1 & 0 & $\mathrm{X}^{*}$ \\
\hline 3 & 1 & 1 & 0 & $\mathrm{X}^{*}$ \\
\hline 4 & 1 & 1 & 1 & 1 or 0 \\
\hline
\end{tabular}

*X represents Not Applicable

Table 1: Truth Table depicting the Working of All Sensors in Conjunction.

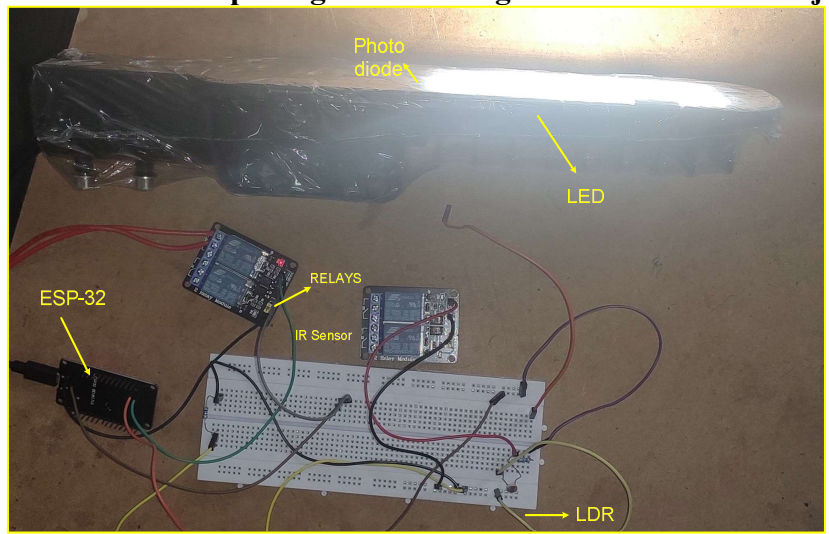

Fig 2: Hardware Prototype of the Proposed System Demonstrating its Working.

\section{Result \& Cost Analysis:}

The proposed system could be implemented in any city of India, which is in the list of upcoming Smart Cities. An attempt is made in this section to show the economic feasibility of the system and savings by considering the proposed system for 100 street lights and each light is rated for $100 \mathrm{~W}$.

Working hours of a street light

$\begin{array}{ll}= & 12 \text { hours } \\ = & 120 \text { units/day } \\ = & 43800 \text { units/year } \\ = & \text { Rs. } 1,53,300 /- \text { per year } \\ = & \text { Rs. } 60,000 /-.\end{array}$

For 100 street lights Energy Consumption

Total Energy consumption $=120 * 365$ days

Electricity Bill $=43800 * 3.5$ (considering Rs. 3.5 per unit)

Total investment (for 100 street lights)

Savings:

Light will be working for 7 hours a day (approximately).

Saving

Energy saving

Electricity bill saving $=18250 *$ Rs. 3.5

$$
\begin{array}{ll}
= & 5 \text { hours } \\
= & 50 \text { units } / \text { day } \\
= & \text { Rs. } 64,000 /- \text { per year }
\end{array}
$$

(approx.)

Hence, the payback period of investments is about one year. 


\section{Conclusions}

This paper presented a cost effective and efficient smart street lighting solution. The proposed system utilizes three different sensors, a relay and a controller to operate the street lights. Various conditions like light availability, seasonal changes, climatic variations, vehicle movements, pedestrian detection and most importantly health of the LED light are considered in programming the system. Detailed description of the system along with its working is presented and the cost effectiveness has been demonstrated.

\section{References}

1. G. Shahzad, H. Yang, A. W. Ahmad and C. Lee, "Energy-Efficient Intelligent Street Lighting System Using Traffic-Adaptive Control," in IEEE Sensors Journal, vol. 16, no. 13, pp. 5397-5405, July1, 2016.

2. A. Abdullah, S. H. Yusoff, S. A. Zaini, N. S. Midi and S. Y. Mohamad, "Smart Street Light Using Intensity Controller," 2018 7th International Conference on Computer and Communication Engineering (ICCCE), Kuala Lumpur, 2018, pp. 1-5.

3. D. K. Srivatsa, B. Preethi, R. Parinitha, G. Sumana and A. Kumar, "Smart Street Lights," 2013 Texas Instruments India Educators' Conference, Bangalore, 2013, pp. 103-106.

4. A. Farahat, A. Florea, J. L. M. Lastra, C. Brañas and F. J. A. Sánchez, "Energy Efficiency Considerations for LED-Based Lighting of Multipurpose Outdoor Environments," in IEEE Journal of Emerging and Selected Topics in Power Electronics, vol. 3, no. 3, pp. 599-608, Sept. 2015.

5. P. T. Daely, H. T. Reda, G. B. Satrya, J. W. Kim and S. Y. Shin, "Design of Smart LED Streetlight System for Smart City With Web-Based Management System," in IEEE Sensors Journal, vol. 17, no. 18, pp. 6100-6110, 15 Sept. 15, 2017.

6. F. Campos, A. Simões, I. Sousa, R. Almeida and P. Daniel, "Smart IP - central management system for public lighting in Portugal," in CIRED - Open Access Proceedings Journal, vol. 2017, no. 1, pp. 1479-1481, 10 2017.

7. G. Jia, G. Han, A. Li and J. Du, "SSL: Smart Street Lamp Based on Fog Computing for Smarter Cities," in IEEE Transactions on Industrial Informatics, vol. 14, no. 11, pp. 4995-5004, Nov. 2018.

8. P. T. Daely, H. T. Reda, G. B. Satrya, J. W. Kim and S. Y. Shin, "Design of Smart LED Streetlight System for Smart City With Web-Based Management System," in IEEE Sensors Journal, vol. 17, no. 18, pp. 6100-6110, 15 Sept.15, 2017.

9. M. A. Rodriguez-Hernandez, A. Gomez-Sacristan and D. Gomez-Cuadrado, "SimulCity: Planning Communications in Smart Cities," in IEEE Access, vol. 7, pp. 46870-46884, 2019.

10. R. Brazil, "Lighting the smart city [Built Environment Power]," in Engineering \& Technology, vol. 11, no. 5, pp. 34-37, June 2016.

11. R. Lohote, T. Bhogle, V. Patel and V. Shelke, "Smart Street Light Lamps," 2018 International Conference on Smart City and Emerging Technology (ICSCET), Mumbai, 2018, pp. 1-5.

12. D. K. Srivatsa, B. Preethi, R. Parinitha, G. Sumana and A. Kumar, "Smart Street Lights," 2013 Texas Instruments India Educators' Conference, Bangalore, 2013, pp. 103-106.

13. N. Narendran and Y. Gu, "Life of LED-based white light sources," in Journal of Display Technology, vol. 1, no. 1, pp. 167-171, Sept. 2005.

14. M. Rico-Secades et al., "Evaluation of a low-cost permanent emergency lighting system based on highefficiency LEDs," in IEEE Transactions on Industry Applications, vol. 41, no. 5, pp. 1386-1390, Sept.-Oct. 2005 .

15. M. Magno, T. Polonelli, L. Benini and E. Popovici, "A Low Cost, Highly Scalable Wireless Sensor Network Solution to Achieve Smart LED Light Control for Green Buildings," in IEEE Sensors Journal, vol. 15, no. 5, pp. 2963-2973, May 2015 